\title{
Uma Análise da Participação das Mulheres nos Cursos Técnico em Informática e Ciência da Computação do Instituto Federal do Sudeste de Minas Gerais
}

\author{
Julie Silva Pereira, Luíza Rosa de Moura, Nurian Maria Amâncio Coelho, \\ Gabriela Cardoso Montes, Ivy Oliveira Magesti, Alessandra Martins Coelho \\ ${ }^{1}$ Departamento Acadêmico de Ciência da Computação - Instituto Federal de Educação, \\ Ciência e Tecnologia do Sudeste de Minas Gerais \\ Caixa Postal 45 - CEP: 36180-000 - Rio Pomba - MG - Brasil \\ alessandra.coelhodifsudestemg.edu.br
}

\begin{abstract}
In this paper, we verify at local level the gender issue in Information Technology (IT) area and also in specific situations of each group in the academic environment. Thus, we use a combination of exploratory and quantitative methods. We conclude that, although many women who start a technical course have affinities for the course, few want to enter an undergraduate course in the same area. In addition, in undergraduate courses, there is a large percentage of dropouts. Many factors such as environmental stimuli, shyness, emotional instability, and self-doubt, generally gives the feeling that everything is too much for her, contributing to resulting in a low number of women studying Computer Science.
\end{abstract}

Resumo. Nesta pesquisa, verificamos em nível local a questão de gênero na área de Tecnologia da Informação (TI) e também em situações específicas de cada grupo no ambiente acadêmico. Assim, usamos uma combinação de métodos exploratórios e quantitativos. Concluímos que, embora muitas mulheres que iniciam um curso técnico tenham afinidades com o curso, poucas desejam ingressar em um curso de graduação na mesma área. Além disso, nos cursos de graduação, há uma grande porcentagem de abandono. Muitos fatores, como estímulos ambientais, timidez, instabilidade emocional e insegurança, geralmente dão a sensação de que tudo é demais para elas, contribuindo para resultar em um número reduzido de mulheres estudando Ciência da Computação.

\section{Introdução}

Conforme descrito em [Assunção 2018], independente das camadas sociais, momentos e lugares estudados, historicamente o trabalho da mulher sempre foi exercido com dificuldade. Segundo a autora, às mulheres de classe social alta eram-lhes atribuídas as tarefas do lar, a função familiar. As mulheres das classes sociais mais baixas, visando manter o sustento familiar, estavam presentes no mercado de trabalho em condições precárias e salários baixos, inicialmente em atividades ligadas à agricultura e aos serviços domésticos, passando para os trabalhos nas fábricas e, mais tarde, atividades ligadas a serviços do terceiro setor, funções terceirizadas e trabalhos em tempo parcial.

A partir da década de 90 pode-se perceber o aumento do incentivo às mulheres para que elas pudessem ingressar cada vez mais no mercado de trabalho, buscando a 
sua emancipação financeira [Guimarães et al. 2016]. A educação teve um papel muito importante como instrumento de emancipação, possibilitando a conquista de espaços e funções culturalmente atribuídos aos homens, como profissões ligadas às ciências exatas e à tecnologia. No entanto, elas sempre tiveram de lutar contra os obstáculos impostos pela sociedade. Dependendo da profissão ou cargo exercido, muitas mulheres, independente de sua classe social, passaram por situações de diferenciação salarial, intimidação física, desqualificação intelectual, ou até mesmo de assédio sexual para ingressar em um campo definido [Rago 2001].

No contexto profissional, pode-se observar em [Carvalho 2019] que mulheres com o mesmo cargo e currículo recebem, em média, 35\% a menos em relação ao mesmo profissional do sexo masculino. Esse é um dos grandes motivos mencionados pela autora que desestimulam a mulher no seu ambiente de trabalho a almejar os cargos mais altos.

Apesar da desigualdade salarial entre os gêneros e da pouca participação feminina em cargos de liderança, as mulheres não se escondem, elas crescem e buscam, a cada dia, a sua inserção no mercado de trabalho. Entretanto, na área de tecnologia, há uma enorme diferença entre os gêneros. Isso evidencia que as relações de gêneros instituídas na sociedade influenciam a formação do vínculo com o conhecimento, criando a divisão sexual do trabalho também no campo da ciência [Lima 2013] e deduzindo que as mulheres não são aptas para exercer atividades relacionadas com tecnologia. Contudo, entender melhor os aspectos que podem favorecer a percepção dos motivos pelos quais isto acontece é de grande importância para criar ações e políticas que possam inserir mais mulheres na área [Freitas et al. 2019].

Para entender melhor o processo de inserção da mulher em áreas tecnológicas, faz-se necessário observar como ocorre o processo escolar em todas as suas fases, até a sua inserção no mercado de trabalho. Diversas pesquisas já foram realizadas com o propósito de compreender a inserção da mulher nas áreas de ciência e tecnologia [Lima 2013, Amaral et al. 2017], além de buscar maneiras para incentivar meninas a ingressarem em cursos dessas áreas. Estas pesquisas baseiam-se amplamente em buscas na literatura, no uso de questionários e em conversas com pessoas da área para auxiliar em diferentes perspectivas. Como exemplos podemos citar um estudo sobre as barreiras que impedem meninas a seguirem nas áreas de exatas, sobre a percepção de alunas do Ensino Médio [Aires et al. 2018], a divulgação da área da Computação, fornecendo informações sobre cursos e mercado de trabalho, a partir de palestras e oficinas de programação e robótica [Mochetti et al. 2016], a inserção da mulher na Ciência da Computação [Soares 2001], a baixa quantidade de matrículas e da permanência de mulheres na área da Computação [Carvalho 2019], e o perfil das mulheres da área da Computação através de uma análise dos microdados referentes ao Exame Nacional de Desempenho dos Estudantes (Enade) [Freitas et al. 2019].

Segundo [Aires et al. 2018], uma grande parcela dos alunos que ingressam em cursos da área de Computação possuem noções básicas ou experiência anterior em programação, diferentemente das mulheres que raramente as possui. Existe a cultura de se educar as meninas para ocupações ditas femininas, como a educação para o lar, a docência e outras que exijam paciência e docilidade, enquanto os meninos são estimulados desde a primeira infância a utilizarem brinquedos que desenvolvam as suas habilidades tecnológicas, o que pode torná-los mais seguros nessas áreas no futuro. Ações 
afirmativas, como o Programa Meninas Digitais, da Sociedade Brasileira de Computação, e muitos outros projetos em andamento nas instituições de ensino brasileiras, que incentivam as mulheres a seguirem carreiras ligadas às ciências exatas, possuem um papel muito importante para mudar esse cenário a fim de trazer avanços para a inserção da mulher nesses mesmos espaços.

Tendo em vista o que foi descrito acima e na reduzida presença de mulheres nos cursos de Técnico em Informática e Bacharelado em Ciência da Computação, ofertados pelo campus Rio Pomba, do Instituto Federal de Educação Ciência e Tecnologia do Sudeste de Minas Gerais (IF Sudeste MG), decidimos averiguar as razões para que esta caraterística ainda ocorra nos dias atuais, em específico, na instituição em ensino supracitada.

\section{Metodologia}

O percurso metodológico envolveu os seguintes passos: (i) pesquisa bibliográfica sobre a inserção das mulheres na área da Computação; (ii) coleta de dados sobre ingressantes, concluídos e matriculados no curso de Ciência da Computação; (iii) elaboração de questionários; (iv) convite às alunas e aplicação dos questionários; e (v) análise dos dados.

A partir do sistema acadêmico da instituição, realizou-se uma coleta quantitativa de dados do curso de Ciência da Computação. Esse levantamento permitiu a verificação do número de alunos ingressantes, desistentes, concluídos e matrícula atual dos alunos por sexo, bem como a análise do histórico dos alunos matriculados. Assim, pudemos ter uma ideia da composição das turmas desde o início do curso (período de 2007 a 2020), bem como ocorreram as aprovações nas disciplinas em que há um grande número de retenções (alunos matriculados em 2020, com pelo menos um período concluído).

Após esse levantamento quantitativo preliminar, passamos à elaboração do questionário a ser aplicado a alunas do curso de Ciência da Computação, estruturado com oito questões objetivas, com perguntas sobre o período do curso, cidade de origem, principais motivos para a escolha do curso, facilidade em disciplinas e afinidade com jogos eletrônicos. Ao final, duas questões discursivas completavam o questionário: (1) Ao iniciar o curso alguma coisa fez você mudar de opinião sobre ele? (2) Pretende exercer a profissão? Procuramos correlacionar as respostas anteriores a estas, a fim de extrair informações que fossem mais relevantes. A finalidade foi investigar os motivos que as fizeram optar pelo curso, bem como as intenções de trabalhar na área.

Pensando na questão de verticalização do ensino e que um número muito reduzido de alunas que realizam o curso Técnico em Informática ofertado no campus optam por continuar os estudos na área, ingressando no curso de Ciência da Computação ou outro curso de tecnologia, um questionário também foi elaborado e aplicado a alunas do curso técnico.

O levantamento dos dados e a aplicação dos questionários foram realizados na primeira quinzena de março de 2020. As etapas tiveram seus dados estruturados em tabelas ou gráficos, para que a análise ocorresse de forma clara e objetiva, assim, alcançando os resultados aqui descritos. 


\section{Resultados e Análise de Indicadores}

Esta seção foi dividida em três subseções para melhor validação e visualização de cada etapa realizada no trabalho.

\subsection{Visão geral do curso de Ciência da Computação}

Nesta etapa, buscou-se avaliar o curso Bacharelado em Ciência da Computação em números, no período de 2007 até o primeiro semestre de 2020. O objetivo foi obter uma visão ampla da evasão e do percurso realizado pelas alunas no período estudado.

Conforme podemos observar na Tabela 1, os dados foram separados em cinco colunas: Ingressantes, Desistentes, Concluído (alunos diplomados), Mat. Inst. (matrícula institucional) e Cursando. As informações dessas colunas foram subdivididas em masculino (M) e feminino (F).

Tabela 1. Dados sobre o curso Bacharelado em Ciência da Computação

\begin{tabular}{ccccccccccc}
\hline Ano & \multicolumn{2}{c}{ Ingressantes } & \multicolumn{2}{c}{ Desistentes } & \multicolumn{2}{c}{ Concluído } & \multicolumn{3}{c}{ Mat. Inst. } & \multicolumn{2}{c}{ Cursando } \\
& M & F & M & F & M & F & M & F & M & F \\
\hline 2007 & 32 & 3 & 19 & 1 & 13 & 2 & 0 & 0 & 0 & 0 \\
2008 & 30 & 6 & 14 & 3 & 16 & 3 & 0 & 0 & 0 & 0 \\
2009 & 31 & 5 & 20 & 3 & 11 & 2 & 0 & 0 & 0 & 0 \\
2010 & 26 & 6 & 14 & 2 & 12 & 3 & 0 & 1 & 0 & 0 \\
2011 & 30 & 6 & 20 & 5 & 6 & 1 & 1 & 0 & 3 & 0 \\
2012 & 26 & 7 & 19 & 3 & 7 & 3 & 0 & 0 & 0 & 1 \\
2013 & 35 & 5 & 17 & 4 & 10 & 1 & 3 & 0 & 5 & 0 \\
2014 & 27 & 5 & 12 & 5 & 8 & 0 & 2 & 0 & 5 & 0 \\
2015 & 33 & 3 & 14 & 3 & 4 & 0 & 7 & 0 & 8 & 0 \\
2016 & 35 & 8 & 17 & 3 & 2 & 1 & 5 & 1 & 11 & 3 \\
2017 & 32 & 5 & 12 & 0 & 0 & 0 & 0 & 0 & 20 & 5 \\
2018 & 33 & 3 & 14 & 2 & 0 & 0 & 0 & 0 & 19 & 1 \\
2019 & 35 & 6 & 9 & 3 & 0 & 0 & 0 & 0 & 26 & 3 \\
2020 & 28 & 4 & 0 & 0 & 0 & 0 & 0 & 0 & 28 & 4 \\
\hline Total & $\mathbf{4 3 3}$ & $\mathbf{7 2}$ & $\mathbf{2 0 1}$ & $\mathbf{3 7}$ & $\mathbf{8 9}$ & $\mathbf{1 6}$ & $\mathbf{1 8}$ & $\mathbf{2}$ & $\mathbf{1 2 5}$ & $\mathbf{1 7}$ \\
\hline
\end{tabular}

$\mathrm{Na}$ coluna Ingressantes, temos a quantidade de alunas e alunos que ingressaram no curso desde a sua primeira turma, em 2007. Pode-se observar que desde o início do curso a quantidade de alunas é visivelmente menor do que a quantidade de alunos, mesmo havendo cursos Técnicos na área ofertados pela instituição de ensino. Ao todo, foram 505 alunos matriculados no período analisado, sendo apenas 72 mulheres, cerca de 14,25\% dos ingressantes.

A taxa de evasão do curso analisado é significativamente alta em relação ao número de alunos que estão cursando ou já concluíram, e ela está mais relacionada com os ingressantes pelo Sistema de Seleção Unificada (SISU) do que pelo Vestibular realizado pela instituição. No total, foram 238 desistentes, cerca de 47,13\% do total de ingressantes, o que resultou em uma média de 17 alunos evadidos por ano. A porcentagem de desistência somente das mulheres é em torno de 51,38\%. 
Na coluna Mat. Inst., temos a quantidade de alunos por turma que já concluíram todas as matérias e que ainda precisam defender o Trabalho de Conclusão de Curso.

Considerando o número de 10 turmas integralizadas, ou seja, turmas de 2007 a 2016, temos um total de 105 alunos que colaram grau. Neste período, 16 alunas $(29,63 \%)$ colaram grau e $32(59,26 \%)$ desistiram do curso. Em 2020, o total de alunos matriculados foi de 162, soma das colunas Mat. Inst (matrícula institucional) e Cursando, sendo o número total de alunas atual igual a 19, ou seja, 11,73\% dos matriculados.

\subsection{Análise dos históricos dos alunos do curso de Ciência da Computação}

O próximo passo foi verificar os índices de aprovações nas matérias de Cálculo, Equações Diferenciais Ordinárias, Geometria Analítica e Álgebra Linear e Física, ofertados pelo Departamento de Matemática, Física e Estatística (DMAFE), e as matérias Algoritmos e Estruturas de Dados, Orientação a Objetos e Laboratório de Programação Web ofertadas pelo Departamento Acadêmico de Ciência da Computação (DACC). Nesta etapa foram analisados os históricos de 129 alunos, sendo 15 mulheres e 114 homens. Os alunos ingressantes em 2020 foram desconsiderados por não ter nenhum período concluído até o momento desta pesquisa. Para cada matéria, foram coletadas informações de alunos concluintes, bem como o percentual de alunos que realizaram a matéria uma única vez, sendo aprovada na mesma. Foram desconsideradas informações de quantas vezes cada aluno se matriculou na matéria até ser aprovado, bem como a nota final obtida.

$\mathrm{Na}$ Tabela 2 temos, a título de comparação, a quantidade de alunos matriculados em 2020, que foram aprovados nas componentes curriculares analisadas, bem como a média do IRA, por gênero. O IRA é a média do rendimento escolar final obtida pelo aluno em relação às matérias concluídas, ponderadas pela carga-horária das matérias cursadas. Seu valor pode variar entre 0 (zero) e 100 (cem), de acordo com o rendimento de cada aluno. Com a verificação do IRA, constatamos que a média do rendimento acadêmico das alunas é maior do que a dos alunos sendo, respectivamente, 65,3\% e 57,2\%. As Figuras 1 e 2 complementam, de forma visual, os dados apresentados na Tabela 2, uma vez que apresentam as porcentagens de alunos que foram aprovados realizando as matérias uma única vez.

Tabela 2. Quantidade de alunos matriculados em 2020, aprovados em componentes curriculares e média do IRA

\begin{tabular}{lcclccc}
\hline Matérias & \multicolumn{2}{c}{ Aprovados } & Matérias & \multicolumn{2}{c}{ Aprovados } \\
DMAFE & Alunas & Alunos & DACC & 15 & 97 \\
\hline Cálculo I & 15 & 113 & AEDs I & 13 & 89 \\
Cálculo II & 15 & 78 & AEDs II & 13 & 68 \\
Cálculo III & 8 & 29 & & AEDs III & Alunos \\
EDO & 10 & 37 & & Orientação a Objetos & 13 & 60 \\
GAAL & 15 & 97 & & Lab. Programação Web & 15 & 94 \\
Física I & 15 & 94 & & & & \\
Física III & 9 & 54 & & & & \\
\hline \hline
\end{tabular}

Como podemos visualizar no gráfico representado na Figura 1, temos informações 
dos alunos que conseguiram aprovação nas disciplinas ofertadas pelo DMAFE. Podemos observar que as alunas conseguiram maior aprovação ao realizar a matéria uma única vez, em cinco, das sete matérias analisadas. Comparado com o resultado dos alunos e fazendo a leitura do gráfico, da esquerda para direita, a diferença entre as porcentagens dos grupos foi de $+16 \%,-5 \%,+4 \%,+35 \%,+10 \%,-10 \%,+11 \%$, respectivamente.

Figura 1. Porcentagem de alunos aprovados com a realização de uma única matrícula em matéria ofertada pelo DMAFE

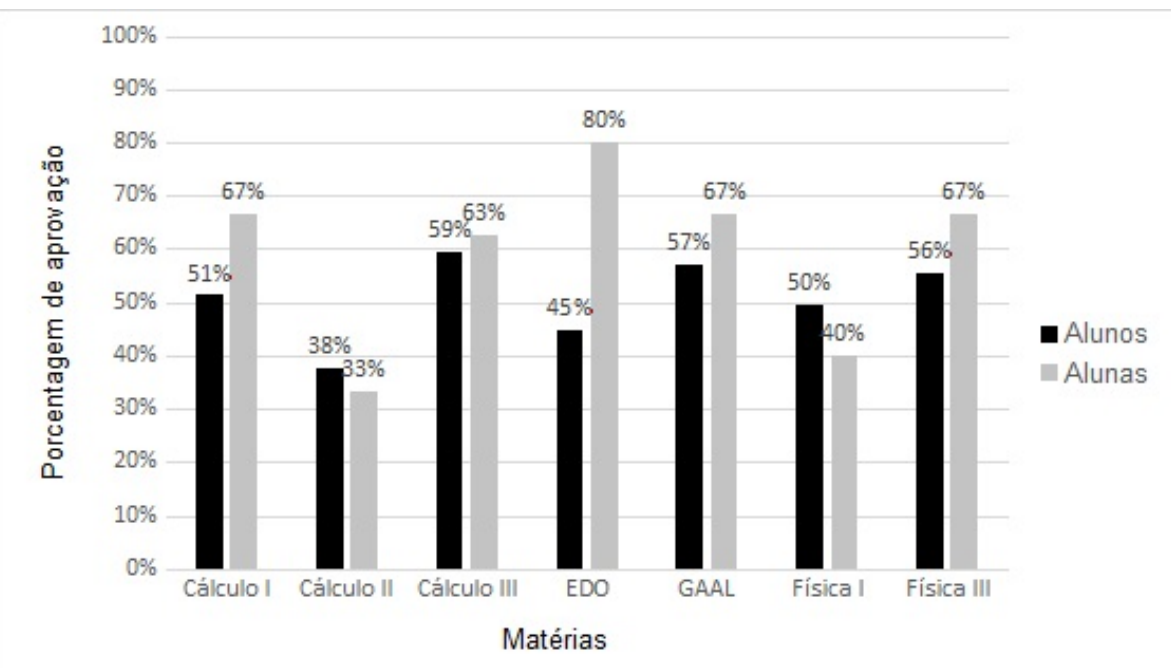

As informações dos alunos que conseguiram aprovação nas matérias ofertadas pelo DACC encontram-se na Figura 2. Podemos observar que as alunas conseguiram maior aprovação ao realizar a matéria uma única vez, em quatro, das cinco matérias analisadas. Comparado com o resultado dos alunos e fazendo a leitura do gráfico, da esquerda para direita, a diferença entre as porcentagens dos grupos é de $+4 \%,-1 \%,+2 \%,+12 \%$, $+14 \%$, respectivamente.

Figura 2. Porcentagem de alunos aprovados com a realização de uma única matrícula por matéria ofertada pelo DACC

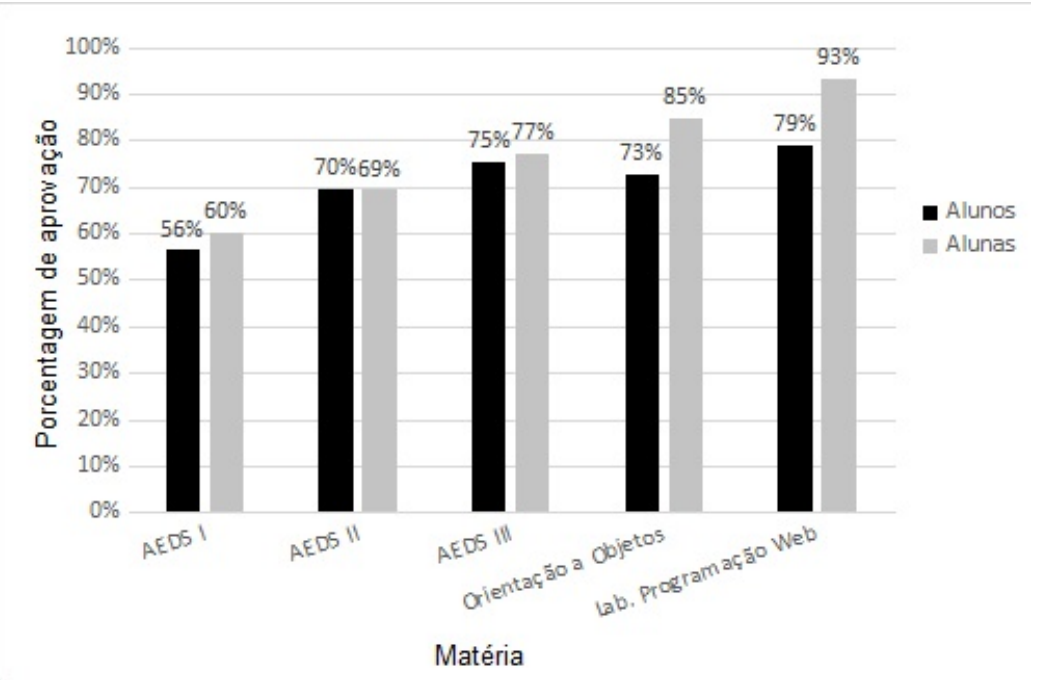




\subsection{Aplicação e análise do questionário}

O questionário foi respondido por 37 alunas, das 42 matriculadas em ambos os cursos em 2020 (20 alunas do curso Técnico Integrado em Informática e 17 do curso de Ciência da Computação). Observou-se que a grande maioria são oriundas de municípios do interior, de pequeno porte.

Perguntadas sobre o principal motivo para a escolha do curso de Ciência da Computação, podemos verificar na Figura 3 que as respontas "Interesse na área"e "Influência de conhecidos que trabalham ou estudam na área", são as que mais influenciaram a escolha, com $82,35 \%$ e $29,41 \%$ respectivamente .

Figura 3. Principal motivo para a escolha do curso de Ciência da Computação.

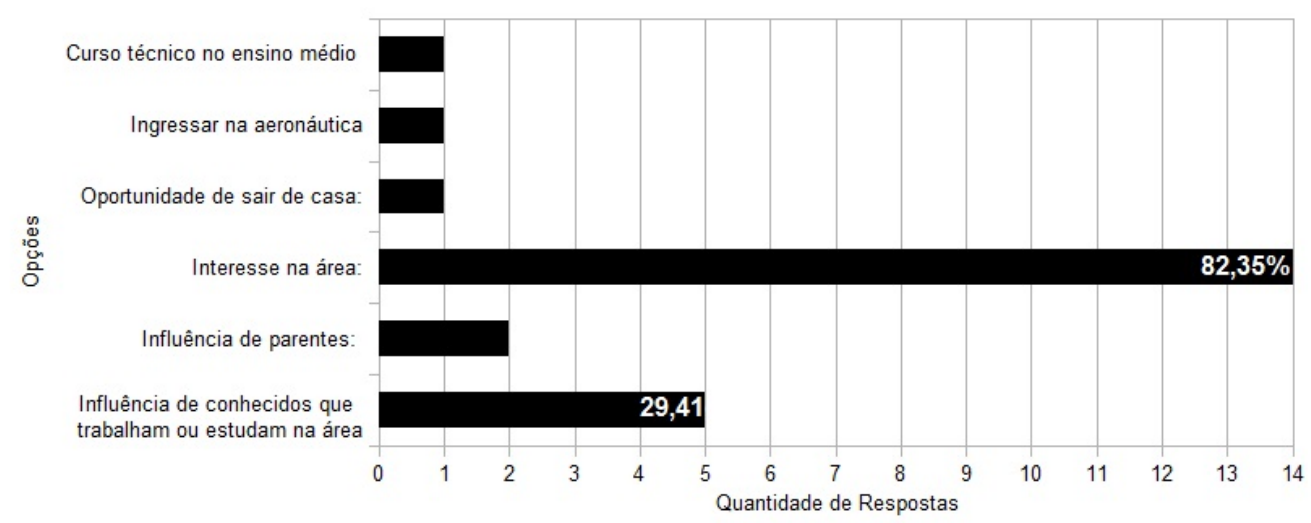

Podemos observar na Figura 4, que 35,3\% das alunas não tiveram nenhuma experiência com a área antes de iniciar o curso superior, $23,5 \%$ realizaram cursos de informática básica e/ou cursos de programação e/ou manutenção de computadores e 41,2\% realizaram cursos técnicos.

Figura 4. Alunas de Ciência da Computação que realizaram algum curso na área de Tecnologia da Informação anterior à Graduação

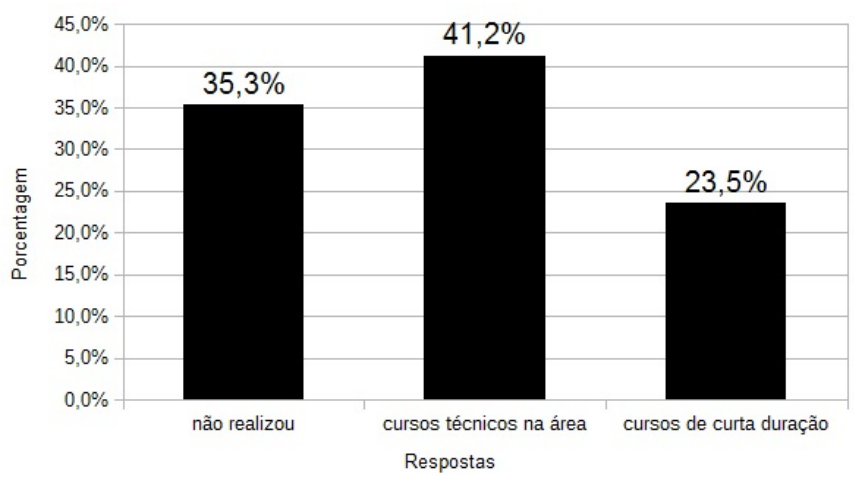

Procuramos saber a opinião das alunas sobre o rendimento delas nas matérias de exatas e de programação, bem como se tinham afinidade com jogos eletrônicos. As respostas seguiram uma escala de 1 (muito pouca facilidade/afinidade) a 10 (muita facilidade/afinidade). Considerando o valor seis como um parâmetro, pois é a nota a ser buscada para a aprovação em uma matéria, compilamos os resultados em um único gráfico, 
onde ter facilidade/afinidade foram considerados os valores seis ou acima deste, quantificados na legenda como "SIM", e com pouca facilidade/afinidade quantificados na legenda como "NÃO”, como pode ser visualizado na Figura 5.

\section{Figura 5. Visão das entrevistadas do curso de Ciência da Computação sobre Facilidade/Afinidade em conteúdos e tecnologia}

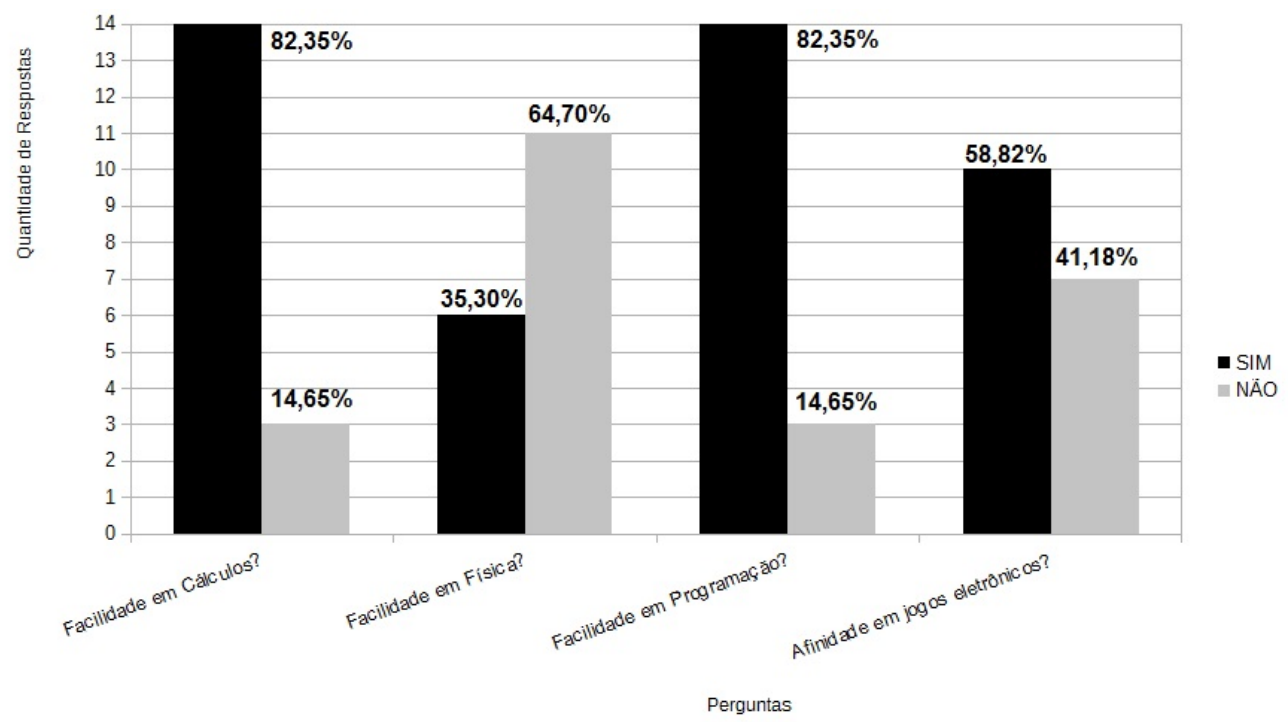

Temos que 82,35\% das alunas consideram possuir facilidade em Cálculo, 35,30\% em Física, 82,35\% em programação e 58,82\% gostam de jogos eletrônicos (que muitas vezes é um indicativo, pelo menos para o sexo masculino, de interesse em realizar um curso na área de tecnologia).

Com as respostas abertas constatamos o quanto as alunas gostam do curso. Algumas delas responderam que não tinham noção do tipo de matéria e conteúdo teriam de realizar em um curso de Ciência da Computação. Disseram que se surpreenderam com os conteúdos ofertados, além da possibilidade de aplicar a Computação em qualquer outra área do conhecimento. Em algum momento, o sentimento de inferioridade por ter dificuldade em algumas matérias, fez surgir pensamentos de desistência do curso, até mesmo com o pensamento de entrar mais rápido no mercado de trabalho. Apesar de terem comentado sobre o preconceito que há na área, como "amigos" dizendo que não deveriam continuar o curso, o fato de se sentir isolada no meio de tantos homens, a quantidade de matérias teóricas, causando desânimo, consideraram que sim, o curso é mais acolhedor do que pensavam; que existe muito incentivo para realizá-lo e que realizar o curso seria ótimo para elas.

Levando em consideração que a instituição de ensino que oferece o curso analisado também oferece outros cursos na área de Tecnologia, como o curso Técnico em Informática que é realizado no mesmo campus do curso superior analisado, qual será o motivo de apenas duas alunas formadas no curso técnico estarem hoje cursando Ciência da Computação e somente outras duas concluíram a graduação na área?

Buscando alguma resposta, um questionário também foi aplicado e respondido por 20, das 23 alunas do curso Técnico em Informática integrado. Revelou-se com os dados obtidos, que $50 \%$ das alunas do técnico vieram estudar na instituição em busca de 
um ensino médio de qualidade, que lhes possibilitasse uma boa classificação no processo de vestibular ou no Exame Nacional de Ensino Médio e, consequentemente, a realização da graduação escolhida na instituição de ensino pretendida, não necessariamente na área de tecnologia. Observamos que das 12 respondentes do $1^{\circ}$ ano do curso Técnico, 58,33\% não pretendem seguir na área e já possuem intenção de realizar um curso superior na área de saúde ou humanas. As demais, 41,66\% ainda não decidiram ou estão indecisas quanto ao curso/profissão a seguir. Já a aluna do $2^{\circ}$ ano (as demais alunas que iniciaram o curso com ela, ou desistiram ou foram reprovadas em 2019) realizará um curso superior na área da saúde. As alunas do $3^{\circ}$ ano relataram dificuldades no decorrer do curso técnico, as desmotivando a continuar na área, além de terem percebido durante a realização do curso, que ele é preferencialmente masculino. Apesar das alunas do $2^{\circ}$ e do $3^{\circ}$ ano relatarem possuírem afinidade em jogos eletrônicos e facilidade na média ou acima da média nas disciplinas de exatas e computação, 62,5\% delas já definiram e pretendem seguir na área de saúde, humanas ou licenciatura. Entretanto, ainda existem três alunas (37,5\%) que ainda não definiram a área que irão seguir, mencionaram possuir interesse na área e facilidade nas disciplinas bases. Percebeu-se grande desmotivação das alunas pela área ao longo do curso técnico.

\section{Conclusão}

Conclui-se, ao analisar os estudantes matriculados nos cursos de Ciência da Computação e Técnico em Informática integrado do IF Sudeste MG - campus Rio Pomba em 2020, que as alunas são bastante dedicadas, tendo em média um IRA maior do que os alunos, o mesmo acontecendo com a média de aprovações, que é maior na maioria das matérias analisadas. Percebeu-se nas respostas das alunas, certo grau de ansiedade para manter as notas altas, aparentando que elas se cobram demais. Desestabilidade emocional e timidez foram outros fatores observados, principalmente nas alunas do curso técnico, fatores estes que contribuem para a alta desistência das alunas em permanecerem na área, já que observamos que, em geral, elas se dão bem nas matérias do curso. Assim, o baixo número de mulheres na área não se dá pela falta de conhecimento ou dificuldades nas disciplinas cursadas, mas sim por outras questões, seja pelo não incentivo no âmbito familiar ou social, o machismo enfrentado em um ambiente majoritariamente masculino ou, até mesmo, pela falta de conhecimento acerca de figuras femininas que atuam ou atuaram na área. Percebemos a importância da realização de projetos, como o Meninas Digitais, nas instituições de ensino fundamental e médio, a fim de dar mais visibilidade aos cursos e às profissões de tecnologia, e assim incentivar mais alunas a realizarem os cursos aqui analisados, bem como apoiar as que já estão realizando, com vistas na redução da evasão ou mesmo retenção nos cursos.

Como trabalhos futuros, pretende-se: (i) analisar mais profundamente o que influencia as alunas do curso técnico, apesar de possuírem, na sua maioria, facilidade em áreas chave para o curso, não terem intenção de realizar um curso superior na área ou exercer a profissão de técnico; (ii) estender a pesquisa para os cursos do campo da Computação de outros campi do IF Sudeste MG e da região; (iii) verificar, dentre as concluintes dos cursos Técnico em Informática e Ciência da Computação, respectivamente, o percentual de mulheres que realizaram curso superior na área e o percentual de mulheres que trabalham na área. 


\section{Agradecimentos}

As autoras agradecem ao FNDE/MEC pela oportunidade de realizarem projetos acadêmicos por meio do PET Conexões de Saberes - Ciência da Computação.

\section{Referências}

Aires, J., Mattos, G., Oliveira, C., Brito, A., Aragão, A. F., Alves, S., Coelho, T., and Moreira, G. (2018). Barreiras que impedem a opção das meninas pelas ciências exatas e computação: Percepção de alunas do ensino médio. In Anais do XII Women in Information Technology, Porto Alegre, RS, Brasil. SBC.

Amaral, M. A., Emer, M. C. F. P., Bim, S. A., Setti, M. G., and Gonçalves, M. M. (2017). Investigando questões de gênero em um curso da área de Computação. Revista Estudos Feministas, 25:857 - 874.

Assunção, L. A. (2018). Os horizontes femininos do trabalho: do chão de fábrica ao teto de vidro. Dissertação (Mestrado em Direito), Universidade Federal de Minas Gerais, Belo Horizonte, Brasil.

Carvalho, F. L. A. N. (2019). Mulheres na informática: estratégias para promover a permanência desse público no curso de licenciatura em informática do instituto federal de educação, ciência e tecnologia do piauí campus teresina zona sul. Trabalho de conclusão de curso (Licenciatura em Informática), Instituto Federal de Educação, Ciência e Tecnologia do Piauí - Campus Teresina Zona Sul. Teresina.

Freitas, B., Cosme, L., and Nascimento, M. (2019). Exame nacional de desempenho de estudantes (enade): Análise do perfil das mulheres dos cursos da Área de computação. In Anais do XIII Women in Information Technology, pages 179-183, Porto Alegre, RS, Brasil.

Guimarães, N. A., Brito, M. M. A. d., and Barone, L. S. (2016). Mercantilização no feminino: A visibilidade do trabalho das mulheres no Brasil. Revista Brasileira de Ciências Sociais, 31:17 - 38 .

Lima, M. (2013). As mulheres na ciência da computação. Revista Estudos Feministas, 21(3):793-816.

Mochetti, K., Salgado, L., Zerbinato, A. V., Souza, B. L., and Avelino, M. R. E. (2016). Ciencia da computação também é coisa de menina! In Anais do X Women in Information Technology, pages 11-15. SBC.

Rago, M. (2001). Trabalho feminino e sexualidade. In História das mulheres no Brasil, pages 578-606.

Soares, T. A. (2001). Mulheres em ciência e tecnologia: ascensão limitada. Química Nova, 24:281 - 285. 